\title{
Designing Credit Agent Incentives to Prevent Mission Drift in Pro-Poor Microfinance Institutions
}

\author{
Cécile Aubert*, Alain de Janvry ${ }^{\dagger}$ and Elisabeth Sadoulet ${ }^{\ddagger}$
}

October 2008

\begin{abstract}
Credit agents in microfinance institutions (MFIs) must be given incentives to acquire information on potential borrowers and select them in accordance with the MFI's objectives. We show that while giving incentives has no cost in for-profit MFIs, it is costly in propoor MFIs: When repayment and wealth are positively correlated, a pro-poor MFI cannot obtain the selection of poor clients in the proportion it wishes with incentives based solely on repayment. It then becomes necessary to audit the share of very poor borrowers selected by an agent in order to provide the latter with adequate incentives. When audit costs are large, pro-poor MFIs may have to forego selection on wealth - and use other targeting devices such as working in impoverished geographical locations. Driven by donor concerns with 'mission drift' away from the poor, audits on the wealth status of clients have been introduced at the level of MFIs. We show that introducing pro-poor incentives requires extending such audits to the level of credit agents.
\end{abstract}

JEL Codes: O16, D82, L31.

Keywords: Micro-Credit, Pro-Poor Objectives, Incentives for agents.

${ }^{*}$ Corresponding Author. Université Bordeaux IV (GREThA) and Toulouse School of Economics (LERNA). E-mail address: Cecile.Aubert@u-bordeaux4.fr

${ }^{\dagger}$ University of California at Berkeley. E-mail address: alain@are.berkeley.edu

${ }^{\ddagger}$ University of California at Berkeley. E-mail address: sadoulet@are.berkeley.edu 


\section{Introduction}

Designing optimal incentives for credit agents has become a major concern for microfinance institutions (MFIs). The existing literature on microfinance has focused almost exclusively on incentive issues between borrowers and lenders. Yet, as credit agents play a critical role in ensuring the success of the MFIs they are working for, they must also be provided with adequate incentives. Without those, they may exert insufficient effort to learn about potential borrowers' characteristics, they may under-report repayments, and they may mis-represent the information they have obtained on potential borrowers. The issue is particularly acute in pro-poor MFIs.

Many pro-poor MFIs derive from non-governmental organizations and have non-profit status. Their objective is to give access to credit to very poor individuals with viable projects. There has, however, been a widely noted 'mission drift' among these MFIs as they increasingly tend to work with clients that are less poor, a drift that has accelerated with rising competition from forprofit MFIs (Weiss and Montgomery, 2005). This has led donors supporting these institutions in search for mechanisms that can induce MFIs to resist mission drift. This paper explores how to design credit agent incentives to achieve this result.

If less-poor borrowers reimburse more on average than very poor borrowers, a pro-poor MFI must strike a balance between financial viability and the selection of very poor borrowers. It wants to lend to an optimal mix of very poor and less-poor borrowers selected among individuals with high ability and most likely to repay. The higher expected repayment rate with less-poor borrowers is used to cross-subsidize loans to very poor individuals, while meeting the zero profit constraint. But incentives for credit agents to select high-ability individuals then tend to conflict with incentives to select very poor individuals, who repay less. For these MFIs, repayment is an incomplete measure of an agent's performance.

To induce search for information on simultaneously poverty levels and ability, one would need to use incentive schemes that are non-monotonous in repayment. But such schemes would give the agent incentives to hide, and possibly withhold, repayment. Observing another variable correlated with wealth is thus necessary. This requires costly audits. To meet their objectives, pro-poor MFIs thus have to bear the additional cost of an audit generating signals on the true type of borrowers by contrast to for-profit MFIs that bear no cost in providing incentives to their credit agents. Audits are, however, not always feasible. In contexts where the cost of finding information on wealth is high, a pro-poor MFI will choose to offer incentives based only 
on repayment performance, as would a for-profit MFI.

An important assumption in our analysis is that wealth and repayment are positively correlated. If less poor borrowers were not more profitable to the lender than the very poor, there fundamentally would be no tension between the outreach objective of the MFI and the viability constraint. There would be no possibility for cross subsidization, and lending to the poor would have to be viable. This would lead to the particular case in which a pro-poor MFI would always lend only to very poor borrowers, and only to very poor borrowers of high ability if acquiring information on ability is not too costly. ${ }^{1}$ Yet a positive correlation is more plausible ${ }^{2}$, at least in areas where mission drift is a concern. A positive correlation arises when less poor borrowers have access to better education, better quality inputs and land, and better social capital that facilitate success in their activity. Empirically, Sharma and Zeller (1997) in Bangladesh, SEF (2003) in South Africa, and Zeller (1998) in Madagascar all find that repayment performance does increase with wealth - the very poor tend to invest in low-return activities and in poorly developed markets where environmental and economic shocks are frequent, while they have low ability to bear risk (Hulme, 2000). This positive correlation, and the conflict it creates between outreach and financial viability, is confirmed by a concern among practitioners that using repayment performance incentives for agents reinforces their drift towards less poor clients. Based on a global survey of microfinance institutions, McKim and Hugart (2005) report that $70 \%$ of the MFIs that implemented an incentive scheme acknowledged that it reduced focus on the target population.

Another assumption made is that the agent is risk neutral with unlimited liability. This (admittedly special) case is particularly useful as it offers a clear benchmark: a for-profit MFI would bear no incentive cost due to delegation in this setting. Any cost borne by a pro-poor MFI stems exclusively from the interaction of the particular objective of a non-profit organization with internal incentives. If the agent was protected by limited liability or was risk averse, additional incentive costs would obviously arise but our main insights would

The remainder of the paper is organized as follows. The next section sketches the practical

\footnotetext{
${ }^{1}$ Agents would still need to be given incentive to acquire information, rather than selecting borrowers randomly. But the particular difficulties we highlight would not arise.

${ }^{2}$ Armendáriz de Aghion and Morduch (2005) show that this correlation may theoretically be positive or negative depending on the context and the specific clientele of an MFI. A negative correlation can arise when repayment is subject to moral hazard from borrowers, and when poorer borrowers are more willing to reimburse than less poor ones. Since we do not consider moral hazard on the side of borrowers in this paper (the probability of reimbursing is a given characteristic of borrowers), we can safely assume a positive correlation.
} 
aspects of staff incentives in for-profit and pro-poor MFIs, and then summarizes the related literature. The model is presented in Section 3. Section 4 shows that using an audit procedure is needed to check the poverty level of selected borrowers. Section 5 characterizes the optimal incentive scheme for a pro-poor MFI under asymmetric information and gives examples of current practices used to combat mission drift. Section 6 offers comments on the implications of rising competition on the ability to select very poor borrowers and concludes.

\section{Incentives in microfinance in practice and in the literature}

\subsection{The incentive issue in practice}

Most for-profit MFIs have by now introduced incentive wages for their credit agents, with bonuses rewarding high repayment rates. McKim and Hugart (2005) surveyed 147 MFIs and report that $72 \%$ have formal staff incentive schemes compared to $6 \%$ only in 1990 and about $30 \%$ in 1999. Among MFIs with such schemes, $83 \%$ give individual incentives, not simply branch incentives. These individual incentives consist in bonuses according to the share of the portfolio not at risk, the number of clients, and the value of the outstanding portfolio. Non-governmental organizations more often use the number of clients, and less often the value of the outstanding portfolio, than banks and non-bank financial institutions, probably as a consequence of their different objectives.

Experts in microfinance have observed a systematic evolution among MFIs in moving up the poverty scale away from the very poor in selecting their clients (Wright and Dondo, 2001; Sustainable Banking for the Poor, 2002) ${ }^{3}$. Bi-lateral donors like USAID have shown increasing concern with this 'mission-drift', which has led the U.S. Congress to pass in 2000 the Microenterprise Self-reliance Act that mandates that half of all USAID microenterprise funds should benefit the very poor. ${ }^{4}$ One of the main reasons for this drift is that it is easier for credit agents to work with less-poor borrowers: as we argued above, very poor borrowers may not repay as often as the less-poor; they are less educated and require more help from credit agents when

\footnotetext{
${ }^{3}$ See also Amin, Rai and Topa (2003).

${ }^{4}$ New legislation in 2003 defines 'very poor' as people living on less than US\$1 a day or being in the bottom $50 \%$ of population below the national poverty line. Accurate and practical poverty assessment indicators that can be used to measure the extent of pro-poor orientation of client MFIs are being actively developed to permit verification that this mandate is being met (IRIS Center, 2004; Cerise, 2008).
} 
preparing and signing loan contracts. ${ }^{5}$ The positive correlation between wealth and repayment plays a central role in this paper.

Selecting the poorest individuals is made difficult by the fact that pro-poor MFIs have few tools to screen borrowers according to their wealth level. To directly screen poor borrowers, pro-poor MFIs mainly use three (imperfect) strategies. One consists in limiting the size of loans; however, non-poor borrowers will still be attracted by these loans when the opportunity cost is borrowing from moneylenders and when larger loans may be expected in the future as part of dynamic incentives to repay (de Wit, 1998). They can also take a multiplicity of small loans from different lenders (McIntosh and Wydick, 2005). Loan size is thus an inadequate instrument for poverty screening (Simanowitz, 2004). A second strategy consists in imposing transactions costs in accessing loans (e.g., frequent repayment installment, required assistance to training sessions) to induce self-selection by the very poor (as theoretically supported by Besley and Coate, 1992). However, these costs reduce the poverty reduction value of the loans, and impose additional costs on lenders. A third strategy is to locate branches in areas where most potential borrowers are very poor, or to work exclusively with social categories such as young rural women or indigenous groups where most members are very poor, provided that their repayment rates are sufficient for financial viability. While geographical or demographic targeting serves this purpose, it has limited use for reaching poor borrowers who are not easily identifiable on the basis of observable characteristics. Strategies available to MFIs to directly screen borrowers according to wealth status are thus quite often not effective, indicating the importance of providing agents with adequate incentives to search for that information.

\subsection{Related literature}

While the literature on micro-credit is extremely large (see, e.g., Morduch, 1999), most studies do not consider the internal agency problems of MFIs, although the issue is raised as an important one in Armendáriz de Aghion and Morduch (2005), and only a few studies consider the issue of screening on wealth. This is in strong contrast to the debate among practitioners who insist that giving incentives to agents is both crucial and difficult. The problem of borrower selection has been extensively addressed in the literature with reference to group lending (see in particular Armendariz de Aghion and Gollier, 2000; Ghatak, 1999, 2000; Ghatak and Guinnane, 1999;

\footnotetext{
${ }^{5}$ Another cause of mission drift is that competition for clients with for-profit MFIs makes it increasingly difficult for non-profit MFIs to use lending to less-poor borrowers in order to cross-subsidize loans to very poor borrowers.
} 
Laffont, 2003). However, group lending does not solve issues related to selecting borrowers according to their wealth status.

Few papers focus on the incentives of micro-credit agents. As they do not address issues related to pro-poor objectives, we offer a complementary analysis. Conning (1999) highlights a specific cost of having credit agents select poor borrowers. He addresses the situation in which credit agents exert unobservable monitoring efforts to ensure that borrowers do not divert too much of their project resources. Richer borrowers own collateral (contrary to our setting), which is observable. They have less incentive to divert resources as they must pledge a larger amount of collateral than poorer individuals. Lending to the poor is thus more costly, due to the added monitoring effort required. Although we also obtain that lending to the poor increases internal costs for an MFI, the mechanism is totally different as we focus on a different type of effort (ex ante information acquisition effort on borrowers' wealth and ability, rather than monitoring). In addition, in Conning's setting, incentive costs come from limited liability, while in ours they arise due to the non-verifiability of wealth levels, and the inadequacy of repayment as a measure of the agent's performance. Other related papers on the incentives of micro-credit agents are Bond and Rai (2002) and Jeon and Menicucci (2005). Both papers consider the possibility that credit agents be corrupted or dishonnest. We will allow for under-reporting of repayments by the credit agent, as in Jeon and Meniccuci (2005), but in a different context.

This paper also relates to the literature on not-for-profit firms. A large part of this literature (Besley and Ghatak, 2005; Francois, 2003; Rowat and Seabright, 2006) assumes that the employees of such firms will be 'motivated'; they require lower wages in equilibrium. We focus by contrast on how to design incentive schemes to align the interests of selfish - or insufficiently motivated $^{6}$ - workers with the non-profit objective of their employer. In stark contrast to these papers, we obtain that incentive costs are higher in a non-profit MFI than in a for-profit as it is more difficult to observe a variable correlated to the non-verifiable non-profit objective.

\footnotetext{
${ }^{6}$ If credit agents were to some extent 'motivated', incentive constraints would change but our main insights would still carry on as long as information acquisition costs are high compared to the motivation benefit obtained by selecting poor borrowers.
} 


\section{The model and some benchmarks}

An MFI lends to individuals who have independent projects. It uses agents as intermediaries to screen borrowers. The potential borrowers considered throughout the paper are all poor, in the sense that they have no collateral they could use in gaining access to (lower-rate) formal banking. In order to avoid confusion, we use the term 'poor' to refer to very-poor borrowers, and 'rich' to refer to less-poor borrowers, even though they also are poor.

\subsection{The economic players}

The borrowers Each individual borrows the same amount to finance a project yielding verifiable benefits. Borrowers are protected by limited liability, and thus only reimburse in case of success. They are differentiated according to their 'ability' and their 'wealth'.

Ability. Borrowers differ in their ability to generate revenues (their probability of success). The expected gain of 'able' $(A)$ borrowers is higher than that of 'unable' $(U)$ ones, which is normalized to 0 ; we assume that individuals prefer to borrow. The proportion of able individuals in the population of potential borrowers is denoted $\mu^{A}$.

Wealth. Borrowers can also be distinguished according to their wealth level: They are either 'rich' $(r)$ or 'poor' $(p)$. 'Rich' borrowers have a positive initial wealth level that is not pledgable (e.g., illiquid or non monetary assets, such as buildings or land with no title or common property rights, or social capital). 'Poor' borrowers have no wealth. Borrowers' wealth is not verifiable, and cannot be used as a condition to obtain a loan. ${ }^{7}$ The proportion of poor potential borrowers is denoted $\mu^{p}$. Moreover, the pool of poor potential borrowers of each ability level is assumed to be large compared to the amount of loanable funds (the current coverage of MFIs is indeed quite limited).

The proportion of able individuals, $\mu^{A}$, is taken to be the same among rich and poor. ${ }^{8}$ But rich able borrowers have higher expected revenues: the expected gain from the borrower's

\footnotetext{
${ }^{7}$ MFIs can impose non-monetary costs on borrowers (like attending regular meetings, filing forms) to sort out borrowers according to wealth. Yet there is a general agreement that these are not sufficient to deter borrowers who are not very poor but yet do not have access to the formal lending market. From a theoretical perspective, imposing non-monetary costs would allow some sorting: able borrowers, who have the highest expected revenues from getting a loan, would be more willing to bear high costs. But it would not be possible to select given proportions of able borrowers according to their wealth level.

${ }^{8}$ Extending the framework to the case where rich borrowers are also more likely to be able (different proportions $\left.\mu_{r}^{A} \neq \mu_{p}^{A}\right)$ can be done, but does not add to the main result.
} 
project, net of the subsistence amount that he must be left with, is normalized to one for a rich able borrower; it is lower, and worth only $\alpha$ on average, with $\alpha \in] 0,1[$, for a poor able borrower.

Success also yields a non-monetary benefit $V$ for the borrower: A borrower who obtains a loan and is successful in repaying builds a reputation and will obtain loans from other sources in the future; he also obtains some social capital, possibly trust from his customers and suppliers, and some expertise and skills so that his future prospects are improved ${ }^{9}$. It is assumed that $V \geq \alpha$, i.e., most of the benefits of a success are long-run.

Table 1 summarizes the characteristics of potential borrowers ${ }^{10}$.

Table 1: Potential borrower types

\begin{tabular}{c|c|c|c} 
Ability & Wealth & Proportion & Expected gain \\
\hline Able & Rich & $\mu^{A}\left(1-\mu^{p}\right)$ & 1 \\
& Poor & $\mu^{A} \mu^{p}$ & $\alpha$ \\
Unable & Rich & $\left(1-\mu^{A}\right)\left(1-\mu^{p}\right)$ & 0 \\
& Poor & $\left(1-\mu^{A}\right) \mu^{p}$ & 0
\end{tabular}

Any contract that is attractive to an able borrower is also attractive to an unable one, as the latter never repays. Under our assumptions, poor and rich unable borrowers have the same expected monetary and non-monetary gains from a loan (zero). Later in the text (Section 5.2. and Appendix 1), we will point out to modifications that apply when poor borrowers obtain a non-monetary benefit (such as social capital) simply from obtaining a loan.

The credit agent The credit agent employed by the MFI can invest to obtain information on borrowers' wealth and ability. The agent has no pro-poor preferences himself. He is risk neutral and not protected by limited liability. His utility is $w-C$ when he incurs a $\operatorname{cost} C$ to obtain information and is paid $w$. The strong assumption of risk neutrality without limited liability means that we will derive lower bounds on the cost of incentives, as this is the case for which it is the easiest to induce a given behavior. Yet, we will show that the non-profit objective of

\footnotetext{
${ }^{9}$ See e.g., Kaboski and Townsend (2005) for empirical estimates of the benefits of microfinance at the village level in Thailand - these benefits include improved job mobility and income smoothing in case of bad shocks.

${ }^{10}$ Our assumptions can be interpreted as follows: Ability is needed to select a profitable project and manage it; Wealth is correlated with assets (such as education, social capital, etc.) that improve the returns from a suitably selected and managed activity. We could have assumed that rich borrowers gain more, even when they are not able. This would have had little impact on our results: As long as rich unable borrowers reimburse less than able rich borrowers, it remains optimal to lend in priority to able borrowers, for cross-subsidization.
} 
pro-poor MFIs makes it difficult to give incentives, even in this most favorable setting.

The agent obtains information for sure (without loss of generality under risk neutrality ${ }^{11}$ ) if he incurs costs $C^{a}$ for information on ability, $C^{w}$ for information on wealth, and $C^{a, w}$ for information on both ability and wealth, with $\min \left\{C^{a}, C^{w}\right\}<C^{a, w} \leq C^{a}+C^{w}$ to reflect possible economies of scope. This information is non-verifiable, so that the agent can pretend that he is informed even though he is not (and he can also pretend that the information is favorable to selecting the borrower even though it is not).

In addition, the agent can withhold part of the repayment: he can choose to report a repayment $\tilde{\rho}$ lower than the actual repayment $\rho$, and cash the difference. The value of this difference should be discounted to account for the need of hiding the amount withheld and for reputation and other costs if borrowers complain. Theft therefore earns a gain of $\lambda(\rho-\tilde{\rho})$, where $\lambda \in] 0,1]$ (as is routinely assumed in the literature on corruption).

The micro-finance institutions We compare two types of micro-finance institutions, forprofit and 'pro-poor'. Both are subject to a viability constraint that states that they must earn a minimal return of $\underline{\Pi}$ per loan ${ }^{12}$. The larger the profitability target, the less freedom the credit institution will have in choosing borrowers. We take the total amount of loanable funds as given.

To consider the most interesting case, we will assume that the expected repayment for poor able borrowers is below the minimum level needed by an MFI: $\alpha<\underline{\Pi}<1$. Under this assumption, an MFI that lends to poor borrowers will need to cross-subsidize them by richer borrowers; it will never be able to lend only to poor borrowers.

For-profit MFIs design incentive schemes for their agents so as to maximize the expected value of repayment minus the costs of investing and rewarding the agent. We assume that the objective function of a pro-poor MFI is to maximize the welfare of the poorer individuals. Appendix 1 shows that provided $V \geq \alpha$ (as assumed), the program reduces to maximizing the share of poor borrowers with high ability in the pool of borrowers, subject to the viability constraint, while setting repayment at its maximal level. This qualifying condition on $V$ can

\footnotetext{
${ }^{11}$ As all actors are risk-neutral, adding uncertainty in the information acquisition process would have us reason in expected values, instead of certain values, but would not change the results. Potential borrowers have no way to strategically use the possibility that the agent makes mistakes or does not learn information despite exerting effort.

${ }^{12}$ Note that the net profit made by an MFI may be negative if the MFI has access to subsidized funding or resources from other for-profit activities. For instance, BRAC, in Bangladesh, uses for-profit activities to help cross-subsidize unprofitable loans. We do not consider these other activities here as they are otherwise not related to our concern.
} 
be interpreted as follows: lending to able individuals provides permanent or long-term gains $V$ larger than the one-time improvements in the welfare of the poor $\alpha$ that would come from giving away the loan. Expected repayment equals the expected gain from the project. The average repayment rate is denoted $\rho$.

Let $y_{i}^{k}$ be the proportion of borrowers of wealth $k, k=r, p$, and ability $i, i=A, U$, required by the MFI, and $x_{i}^{k}$ the proportion actually selected by the agent. The MFI can base the agent's wage on the level of repayment he obtains. If it wishes so, the MFI can use an audit procedure in order to obtain at some cost $C^{s}$ a contractible signal $\sigma$ on the proportion of poor individuals $x_{A}^{p}+x_{U}^{p}$ actually selected by the agent.

\subsection{The full information benchmark}

It is useful to compute the benchmark case of an MFI with perfect information on the ability and wealth of all potential clients. The expected profit of an MFI that pays an agent a wage $w$ to select proportions $y_{A}^{p}$ and $y_{A}^{r}=1-y_{A}^{p}$ of able borrowers is $\left[1-y_{A}^{p}(1-\alpha)\right]-w$.

Under full information, since rich borrowers have a higher expected gain, a profit maximizing MFI will only lend to rich able borrowers: $y_{A}^{r}=1$.

If the expected repayment for poor able borrowers was above the minimum level needed by an MFI $(\alpha \geq \underline{\Pi})$, a pro-poor MFI would select only poor able borrowers, and make a positive profit on the operation. But with $\alpha<\underline{\Pi}<1$, a pro-poor MFI will lend to rich able borrowers in order to obtain profits in excess of its profitability target and use these profits to finance poor able borrowers. With this cross-subsidization, the viability constraint is binding and the MFI lends to a proportion $y_{A}^{p}=\frac{1-\underline{\Pi}}{1-\alpha}<1$ of poor able borrowers.

\section{The limitations of repayment incentives}

From now on, we assume that the MFI must give incentives to the credit agent to search for information on borrowers' characteristics. For a profit-maximizing MFI, giving adequate incentives to its agent is easy: A wage related to borrowers' repayment enables to implement the first best as repayment is perfectly correlated with the profit objective. The problem is more difficult for a pro-poor MFI. To better understand the need for a pro-poor MFI to audit borrowers' wealth, let us assume for the moment that such an audit is not available. 


\subsection{Incentives in the absence of audit}

When no audit is undertaken, the only verifiable variable available to the MFI is repayment. As the agent can report a lower repayment than the actual one, incentive constraints incorporate the need for the agent to gain more by reporting truthfully than by under-reporting and keeping part of the repayment.

Assume that the MFI wishes the agent to become informed on both wealth and ability, and to select a proportion $y_{A}^{p}$ of poor able borrowers, and $1-y_{A}^{p}$ of rich able borrowers (the logic of the argument would be similar if the MFI wanted the agent to learn only wealth, and select a proportion $y^{p}$ of poor borrowers). The expected wage paid to the agent is $w(\tilde{\rho})$. It cannot be increasing for all values, as the agent would have incentives to either learn wealth and ability and select only rich able borrowers, or to learn only ability and select able borrowers independently of their wealth. Nor can the wage be fully decreasing as the agent would have incentives to report no repayment.

The MFI program writes as follows:

$$
\max _{\left\{y_{A}^{p}, w(.)\right\}} y_{A}^{p}
$$

subject to

$$
\begin{aligned}
& w\left(1-(1-\alpha) y_{A}^{p}\right)-C^{a, w} \geq 0 \quad(P C) \\
& w\left(1-(1-\alpha) y_{A}^{p}\right)-C^{a, w} \geq \max _{\tilde{\rho}, x_{A}^{p}, x_{A}^{r}} w(\tilde{\rho})+\lambda\left[\left(x_{A}^{p} \alpha+x_{A}^{r}\right)-\tilde{\rho}\right]-C^{a, w} \\
& \text { s.t. } \tilde{\rho} \leq\left(x_{A}^{p} \alpha+x_{A}^{r}\right) \quad(I C)^{\emptyset} \\
& w\left(1-(1-\alpha) y_{A}^{p}\right)-C^{a, w} \geq \max _{\tilde{\rho}, x_{A}} w(\tilde{\rho})+\lambda\left[\left(1-(1-\alpha) \mu^{p} x_{A}\right)-\tilde{\rho}\right]-C^{a} \\
& \text { s.t. } \tilde{\rho} \leq\left(1-(1-\alpha) \mu^{p} x_{A}\right) \quad(I C)^{w} \\
& w\left(1-(1-\alpha) y_{A}^{p}\right)-C^{a, w} \geq \max _{\tilde{\rho}, x^{p}} w(\tilde{\rho})+\lambda\left[\left(1-(1-\alpha) \mu^{A} x^{p}\right)-\tilde{\rho}\right]-C^{w} \\
& \text { s.t. } \tilde{\rho} \leq\left(1-(1-\alpha) \mu^{A} x^{p}\right) \quad(I C)^{a} \\
& w\left(1-(1-\alpha) y_{A}^{p}\right)-C^{a, w} \geq \max _{\tilde{\rho}} w(\tilde{\rho})+\lambda\left[\mu^{A}\left(1-(1-\alpha) \mu^{p}\right)-\tilde{\rho}\right] \\
& \text { s.t. } \tilde{\rho} \leq\left(\mu^{A}\left(1-(1-\alpha) \mu^{p}\right)\right) \quad(I C)^{a, w}
\end{aligned}
$$

and the viability constraint $\left(1-(1-\alpha) y_{A}^{p}\right)-w\left(1-(1-\alpha) y_{A}^{p}\right) \geq \underline{\Pi}$.

$(P C)$ denotes the participation constraint; $(I C)^{a}$ ensures that the agent prefers to learn 
about ability rather than just wealth, $(I C)^{w}$ that he learns about wealth rather than just ability, and $(I C)^{a, w}$ that he learns about both rather than nothing; $(I C)^{\emptyset}$ is the incentive constraint ensuring that the agent selects adequate proportions when he is fully informed.

In these equations, the left-hand side expression is the wage received by the agent who learns about wealth and ability and selects $y_{A}^{p}$ as requested by the MFI. The right-hand side expressions are the wage received from the optimal selection of borrowers and $\tilde{\rho}$ under alternative information choices. If the slope of $w($.$) is lower than \lambda$, the agent has incentives to withhold repayment. This is not an issue for a for-profit MFI, which cares only about repayment: it can always offer a sufficiently steep incentive wage, while adjusting the fixed part of the wage to compensate for a higher variable part.

To the contrary, we show now that two incentive constraints faced by a pro-poor MFI cannot be satisfied. The best the MFI can do is to offer a wage such that $w(\tilde{\rho})$ is maximum for the average repayment with the desired proportions, at $y_{A}^{p} \alpha+\left(1-y_{A}^{p}\right)=\left[1-(1-\alpha) y_{A}^{p}\right]$. Denote $\bar{w} \equiv w\left(1-(1-\alpha) y_{A}^{p}\right)$. Then $w(\tilde{\rho}) \leq \bar{w}$ for all $\tilde{\rho}$. This means that if the agent is informed about wealth and ability, he has incentives to select only rich able borrowers, and keep part of the repayment so that $\tilde{\rho}=\left[1-(1-\alpha) y_{A}^{p}\right]$, while actual repayment is 1 .

This behavior ${ }^{13}$ provides him with maximal payment plus the value stolen, $\lambda(1-\alpha) y_{A}^{p}$. Thus the MFI cannot satisfy the incentive constraint $(I C)^{\emptyset}$ that ensures that the agent, when informed, selects adequate proportions whenever $\lambda>0$.

A similar reasoning applies to the incentive constraint ensuring that the agent learns about wealth.

Proposition 1 Contrary to a for-profit MFI, a pro-poor MFI cannot obtain the selection of poor able borrowers in the proportion it wishes with incentives based solely on repayment.

To summarize, due to the risk of under-reporting ${ }^{14}$, a pro-poor MFI needs to use additional tools, such as costly audits, in order to induce adequate selection of poor borrowers. The need

\footnotetext{
${ }^{13}$ It might be that stealing more provides the agent with even more gain than the one considered here. This would only reinforce our result.

${ }^{14}$ From a positive perspective, there are other reasons why non-monotonic schemes may not be implementable. This is true in particular if agents needs to exert effort to monitor borrowers; then the incentive scheme cannot reconcile the need for a bonus in case of high repayment to induce monitoring effort, and a bonus in case of low repayment to induce selection of poor borrowers. This problem could be resolved by separating tasks and having different agents select borrowers, monitor them, and collect payments. Yet these tasks are likely to be complementary and involve economies of scope. And theft remains possible with task separation so that our impossibility result remains.
} 
to obtain a verifiable variable related to wealth implies an intrinsically higher agency cost than in for-profit MFIs.

\subsection{Using signals on wealth}

In the remainder of the paper, we thus consider audits on borrowers' wealth as instruments to be added to repayment incentives: the MFI can observe at cost $C^{s}$ a contractible signal $\sigma$ on the proportion of poor individuals actually selected by the agent. ${ }^{15}$ We will assume that the cost of the audit is not so large that it forces the MFI to lend to fewer poor able borrowers than when it uses only repayment incentives and suffer from theft by the agent.

The signal may for instance arise from a survey on a random sample of the clients selected by the agent, with the objective of assessing the poverty status of these clients. The observed proportion of poor borrowers in the sample is an unbiased estimation of the true proportion $x^{p}$ of poor able borrowers: $\sigma=x^{p}+\epsilon$, with $\mathbf{E}(\epsilon)=0$. Under risk neutrality, the agent only takes into account expected values, and precision $(\operatorname{var}(\epsilon)$, related to the size of the sample) does not matter. Here, choosing the lowest sample size, at the minimal $\operatorname{cost} C^{s}$, is optimal. ${ }^{16}$

With an audit on wealth, the MFI is able to offer strictly increasing repayment incentives, while still inducing borrower selection on wealth. Strictly increasing repayment incentives will prevent theft provided that the derivative of the wage with respect to repayment is higher than $\lambda, \lambda \leq 1$. This constraint applies to all subsequent programs of the MFI; we will omit it in these programs to simplify the exposition.

\section{The optimal incentive scheme for a pro-poor MFI}

This section characterizes the best outcome a pro-poor MFI can obtain under asymmetric information on both wealth and ability. The MFI can use two instruments in order to induce

\footnotetext{
${ }^{15}$ The signal is an ex-post one. See Crémer and McLean (1988) and Riordan and Sappington (1988) for more on correlation and the costs of asymmetric information. Rai (2002) proposes a scheme in which auditing is costless. This, however, requires that borrowers can be sufficiently punished in case of theft or misreporting. In our setting, borrowers have no resources that can be seized.

${ }^{16}$ If the agent was risk averse, he would require a risk premium linked to the precision of the signal. Choosing a more precise (and more costly) signal might be optimal to reduce the risk borne by the agent. The size of the sample of surveyed clients would be determined to obtain a lower $\operatorname{var}(\epsilon)$. Risk aversion would thus impose additional incentive costs, as is usual in moral hazard settings. Note also that one could allow for a possible bias $(\mathbf{E}(\epsilon) \neq 0$ ), provided that the MFI corrects for it (in the following, one would have to substract the expected value of the bias to the signal, when comparing it to the target proportion of poor).
} 
two related tasks: Wages increasing with repayment allow to induce information acquisition on ability; and wages conditional on a signal on poverty status can induce an adequate selection on wealth. The institution must choose whether it will use both instruments, one only, or none. This choice is determined by comparing the number of poor able borrowers obtaining a loan in equilibrium in each case.

\subsection{The best incentive compatible outcome for each degree of information}

For each degree of information acquisition, the MFI must bear real information costs: the costs incurred by the agent, that are reimbursed through his wage (e.g., $C^{a}$ for information on ability only, etc.), and the audit cost $C^{s}$ when the MFI requires information on wealth. The best possible outcome for the MFI is to have all incentive and participation constraints satisfied at no additional costs than these real costs. We show that it can be attained with simple wages that are linear in repayment and in the signal on wealth ${ }^{17}$. To prove that such wages exist, it is enough to exhibit one of them, which is what we do below. Appendix 2 details the general program of a pro-poor MFI that induces information acquisition on both wealth and ability.

To simplify future expressions, let us denote by $\rho^{A}=\left(\mu^{r}+\alpha \mu^{p}\right)=\left(1-\mu^{p}(1-\alpha)\right)$ the average repayment rate among able individuals, i.e., with poor and non-poor in proportions equal to what they are in the population.

A few features of the different options are worth noting. First, with linear wages, the fixed part $W$ is always adjusted to have the participation constraint binding: the agent gets no information rent. Incentive costs are thus exactly equal to information acquisition costs for the MFI. Second, when the MFI has information on wealth, it will choose the highest proportion of poor borrowers compatible with the viability constraint. As poor borrowers reimburse less on average, this highest proportion is obtained when the viability constraint is exactly binding.

Option $[\emptyset]$ - No incentive When the MFI gives no incentives, the agent's wage is set at its reservation level, zero. The agent selects borrowers randomly. The proportion of poor able borrowers is then what it happens to be in the population, $\mu^{A} \mu^{p}$. This option can only be

\footnotetext{
${ }^{17}$ As is usual when the agent is risk neutral and has unlimited liability, there are many possible wage schemes that also implement this outcome. Simple wages are here without loss of generality. If the agent was risk averse, linear schemes would generally not be sufficient. And the MFI would have to provide the agent with a risk premium to compensate for the risk associated with repayment and audit uncertainty - hence additional costs. As this is standard in moral hazard contexts, we do not detail it further here.
} 
viable if the expected return for the MFI, $\left[1-\mu^{p}(1-\alpha)\right] \mu^{A}=\mu^{A} \rho^{A}$, is larger than $\underline{\Pi}$. This condition will only hold when poor able individuals are sufficiently profitable ( $\alpha$ high) or when the proportion of rich able individuals is high in the population $\left(\mu^{A}\left(1-\mu^{p}\right)\right.$ high $)$ - which is unlikely in areas in which microfinance institutions operate. This option is thus likely to be chosen only for specific geographic areas.

Option $[a]$ - Incentives to learn about ability In order to induce information acquisition on ability, the MFI must use a wage increasing with repayment, for instance a linear wage, $w=\omega \rho+W$. The variable part $\omega$ must be large enough to induce information acquisition on ability, but not too large as the agent would otherwise also learn about wealth, in order to select only rich able borrowers. ${ }^{18}$ The fixed fee $W$ adjusts to have the agent's participation constraint binding: $W=C^{a}-\left[1-\mu^{p}(1-\alpha)\right] \omega$. The expected return of the MFI is then $\left[1-\mu^{p}(1-\alpha)\right]-C^{a}=\rho^{A}-C^{A}$. Assuming it to be higher than the minimum level $\underline{\Pi}$, the MFI lends only to able borrowers, and $y_{A}^{p}$ is the proportion of poor individuals among able ones: $y_{A}^{p}=\mu^{p}$.

Option $[w]$ - Incentives to learn about wealth In order to induce information acquisition on wealth only, the MFI should use an audit procedure, and condition the agent's wage on the signal obtained, $\sigma$. Given incentive constraints, a wage scheme implementing the optimal outcome consists of three terms: a fixed term $W$; a repayment bonus $\omega \rho$ (with $\omega \geq \lambda$ ) to avoid theft; and a penalty proportional to the difference between the signal and the required proportion of poor borrowers, $y^{p}$. The expected wage is thus $w(\sigma, \rho)=W+\omega \rho-s \mathbf{E}\left|y^{p}-(\sigma+\epsilon)\right|$. Expected repayment will be $\mu^{A}\left(1-y^{p}(1-\alpha)\right)$.

The MFI wants to lend to a sufficient proportion of richer borrowers to satisfy its viability constraint; It therefore does not offer a bonus strictly increasing in the proportion of poor borrowers selected, but one increasing up to the preferred proportion, and decreasing above it. This explains the shape of the wage we consider: the agent is penalized when selecting less or more poor borrowers than $y^{p}$.

\footnotetext{
${ }^{18}$ Two incentive compatibility constraints model these requirements: $\omega\left[1-\mu^{p}(1-\alpha)\right]-C^{a}=\omega \rho^{A}-C^{A} \geq \omega \mu^{A} \rho^{A}$, which translates into $\omega \geq \underline{\omega} \equiv \frac{C^{a}}{\left(1-\mu^{A}\right) \rho^{A}}$; And $\rho^{A} \omega-C^{a} \geq \omega-C^{a, w}$, i.e., $\omega \leq \bar{\omega} \equiv \frac{C^{a, w}-C^{a}}{\mu^{p}(1-\alpha)}$. Depending on the value of the parameters, the two inequalities may not be compatible (if $\underline{\omega}>\bar{\omega}$ ). Non linear wage schemes would then be required to satisfy both incentive constraints. To allow for easy comparison with other options, we assume that parameters are such that some value $\omega$ exists that satisfies both inequalities, while also being larger than $\lambda$ to deter theft.
} 
As the agent is risk neutral and not protected by limited liability, a large enough penalty always ensures adequate effort to obtain information on wealth status, and adequate selection somewhat in line with the maximum fine result by Becker (1968). Repayment incentives must be large enough to avoid theft, but not so large that the agent has incentives to learn about ability and select high-repayment borrowers. Appendix 2 details possible solutions ${ }^{19}$.

The MFI obtains an expected return of $\left[1-y^{p}(1-\alpha)\right] \mu^{A}-C^{w}-C^{s}$. From the viability constraint binding, the number of poor borrowers receiving a loan is ${ }^{20}: y_{A}^{p}=\mu^{A} y^{p}=\frac{\mu^{A}-\left(\underline{\Pi}+C^{w}+C^{s}\right)}{(1-\alpha)}$.

Option $[a, w]$ - Incentives to learn about both ability and wealth Assume now that the MFI wants to induce information acquisition on both characteristics, and a selection of $y_{A}^{p}$ able poor borrowers. It should offer a wage scheme depending on both the signal obtained by auditing borrowers and the repayment rate, $w(\sigma, \rho)$ - where the expected repayment rate is $\rho=\alpha x_{A}^{p}+x_{A}^{r}$, and the signal observed is a function of the proportion of poor individuals selected, $x_{A}^{p}+x_{U}^{p}$.

The agent will always choose the proportions of borrowers in order to maximize his utility, given the information available to him. This is reflected in the incentive constraints. When the agent acts as requested by the MFI, the expected repayment rate is $\alpha y_{A}^{p}+\left(1-y_{A}^{p}\right)=1-(1-\alpha) y_{A}^{p}$. If the agent is informed (and provided $\frac{\partial w}{\partial \rho} \geq \lambda$ to avoid theft), he has no incentives not to select borrowers as requested. The program of a pro-poor MFI writes as:

$$
\max _{\left\{y_{A}^{p}, w(.)\right\}} y_{A}^{p}
$$

subject to

$$
\begin{aligned}
& w\left(\sigma\left(y_{A}^{p}\right), 1-(1-\alpha) y_{A}^{p}\right)-C^{a, w} \geq 0 \quad(P C) \\
& w\left(\sigma\left(y_{A}^{p}\right), 1-(1-\alpha) y_{A}^{p}\right)-C^{a, w} \geq \max _{x_{A}^{p}, x_{A}^{r}}\left\{w\left(\sigma\left(x_{A}^{p}\right), \alpha x_{A}^{p}+x_{A}^{r}\right)\right\}-C^{a, w} \quad(I C)^{\emptyset} \\
& w\left(\sigma\left(y_{A}^{p}\right), 1-(1-\alpha) y_{A}^{p}\right)-C^{a, w} \geq \max _{x_{A}}\left\{w\left(\sigma\left(\mu^{p} x_{A}\right), 1-(1-\alpha) \mu^{p} x^{A}\right)\right\}-C^{a} \quad(I C)^{w} \\
& w\left(\sigma\left(y_{A}^{p}\right), 1-(1-\alpha) y_{A}^{p}\right)-C^{a, w} \geq \max _{x^{p}}\left\{w\left(\sigma\left(x^{p}\right), 1-(1-\alpha) \mu^{A} x^{p}\right)\right\}-C^{w} \quad(I C)^{a} \\
& w\left(\sigma\left(y_{A}^{p}\right), 1-(1-\alpha) y_{A}^{p}\right)-C^{a, w} \geq w\left(\sigma\left(\mu^{p}\right)\right), \mu^{A}\left(1-(1-\alpha) \mu^{p}\right) \quad(I C)^{a, w}
\end{aligned}
$$

\footnotetext{
${ }^{19}$ Assume $\lambda \leq \frac{C^{a, w}-C^{w}}{\left(1-\mu^{A}\right)\left(1-y^{p}(1-\alpha)\right)}$; one of the many solutions is $\omega=\lambda, W=C^{w}-s \mathbf{E}|\epsilon|-\lambda \mu^{A}\left(1-y^{p}(1-\alpha)\right)$ and $s \geq \max \left\{\frac{C^{w}-C^{a}+\lambda\left[1-\mu^{A}+(1-\alpha)\left(y^{p} \mu^{A}-\mu^{p}\right)\right]}{\mathbf{E}\left|y^{p}-\left(\mu^{p}+\epsilon\right)\right|-\mathbf{E}|\epsilon|}, \frac{C^{w}+\lambda \mu^{A}(1-\alpha)\left(y^{p}-\mu^{p}\right)}{\mathbf{E}\left|y^{p}-\left(\mu^{p}+\epsilon\right)\right|-\mathbf{E}|\epsilon|}\right\}$.

${ }^{20}$ If this expression is negative (for $\alpha$ or $\mu^{A}$ very small), this option is not available.
} 
and the viability constraint $\left(1-(1-\alpha) y_{A}^{p}\right)-w\left(\sigma\left(y_{A}^{p}\right), 1-(1-\alpha) y_{A}^{p}\right)-C^{s} \geq \underline{\Pi}$.

As shown in Appendix 2, a simple wage scheme linear in repayment and in the difference between the signal and the recommended proportion of poor borrowers, $w=\omega(\rho)-s\left|y_{A}^{p}-\sigma\right|+W$, will be sufficient to achieve the best outcome. As for the other options, the participation constraint binds and $W=C^{a, w}-\omega\left[1-y_{A}^{p}(1-\alpha)\right]-s \mathbf{E}|\epsilon|$. With such a wage scheme, a high enough penalty $s\left(s \geq \omega(1-\alpha) \mu^{A}\right)$ ensures that if the agent deviates and does not search for information on ability, he selects the number of poor required by the MFI. For $s \geq \omega(1-\alpha) \mu^{A}$, one can rewrite the incentive compatibility constraints as follows:

$$
\begin{aligned}
& \omega\left(\mu^{p}-y_{A}^{p}\right)(1-\alpha)+s\left[\mathbf{E}\left|y_{A}^{p}-\left(\mu^{p}+\epsilon\right)\right|-\mathbf{E}|\epsilon|\right] \geq C^{a, w}-C^{a} \quad(I C)^{w} \\
& \omega\left(1-\mu^{A}\right)\left[1-y_{A}^{p}(1-\alpha)\right] \geq C^{a, w}-C^{w} \quad(I C)^{a} \\
& \omega\left[1-\mu^{A}-(1-\alpha)\left(y_{A}^{p}+\mu^{A}\left(1-\mu^{p}\right)\right)\right]+s\left[\mathbf{E}\left|y_{A}^{p}-\left(\mu^{p}+\epsilon\right)\right|-\mathbf{E}|\epsilon|\right] \geq \quad C^{a, w} \quad(I C)^{a, w} .
\end{aligned}
$$

It is immediate that one can always increase the share of repayment $\omega$ to satisfy all constraints. The agent earns no rent. Hence, whatever the value of the parameters, the MFI can always design a wage such that total internal costs be no more than $C^{a, w}+C^{s}$.

The expected return of the MFI is thus $\left[1-y_{A}^{p}(1-\alpha)\right]-C^{a, w}-C^{s}$. From the viability constraint, the number of poor borrowers receiving a loan is $y_{A}^{p}=\frac{1-\left(\underline{\Pi}+C^{a, w}+C^{s}\right)}{(1-\alpha)}$.

\subsection{How much information acquisition is it optimal to induce?}

Table 2 summarizes the four options that can be available to the MFI, as described in the previous section. In options $\emptyset$ and $a$, the proportions of poor able borrowers lent to will be the ones in the population (restricted to able borrowers for option $a$ ). The optimal choice is the

Table 2: Outreach to able poor and profits for each option

\begin{tabular}{c|c|c} 
Option: Information acquisition & Outreach: Proportion $y_{A}^{p}$ & Net profit \\
\hline No incentive $[\emptyset]$ & $\mu^{p} \mu^{A}$ & $\mu^{A} \rho^{A}-\underline{\Pi}$ \\
Ability $[a]$ & $\mu^{p}$ & $\rho^{A}-\underline{\Pi}-C^{a}$ \\
Wealth $[w]$ & $\frac{\mu^{A}-\left(\underline{\Pi}+C^{w}+C^{s}\right)}{(1-\alpha)}$ & 0 \\
Ability and wealth $[a, w]$ & $\frac{1-\left(\underline{\Pi}+C^{a, w}+C^{s}\right)}{(1-\alpha)}$ & 0
\end{tabular}

scheme leading to the maximum number of loans to poor able borrowers, given the value of the 
parameters. Comparing the numbers of poor in Table 2 leads to conditions delimiting the choice of incentive schemes, that can all be simply written in terms of the share of able borrowers $\mu^{A}$ in the population, the repayment rate $\rho^{A}$, and the different costs of acquisition of information. These conditions are established in Appendix 3, by comparing the different incentive schemes two by two. Figure 1 summarizes the results when the cost of acquisition of information on poverty status $C^{w}+C^{s}$ is lower than the cost of acquisition of information on ability $C^{a}$.

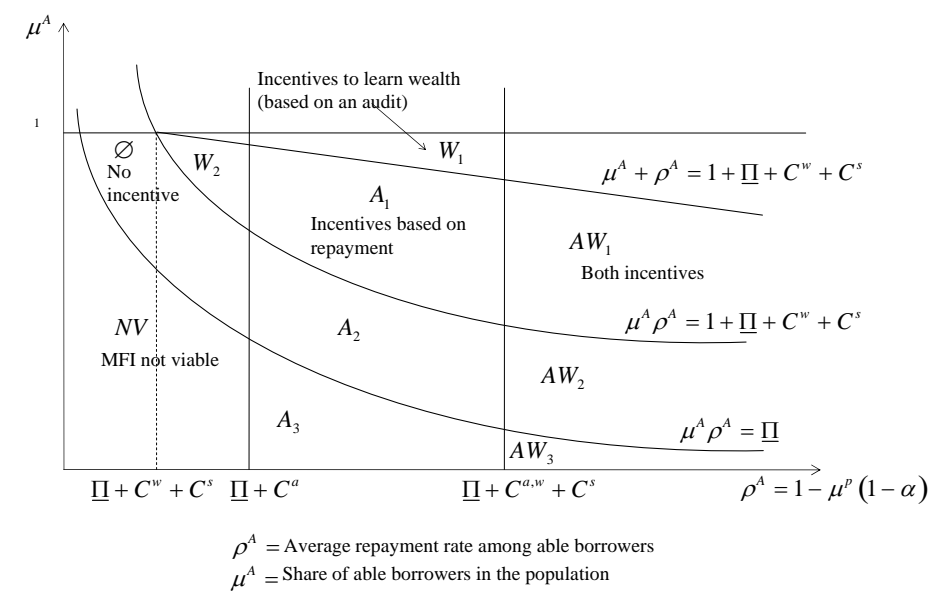

Figure 1: Map of optimal incentive scheme when $C^{w}+C^{s}<C^{a}$

On the horizontal axis, is the average repayment rate $\rho^{A}$ that would be obtained if there was selection on ability only (with poor and non-poor in the proportion encountered in the population). For a very low $\rho^{A}$, the MFI could not cover any cost of acquisition of information and satisfy the minimum profitability $\underline{\Pi}$. As $\rho^{A}$ rises, the MFI could cover the cost of acquisition of information on wealth $C^{w}+C^{s}$, or the cost of acquisition on ability $C^{a}$, or the cost of both $C^{a, w}+C^{s}$, if it so desires. On the vertical axis we report the share of able borrowers in the population, $\left.\mu^{A} \in\right] 0,1[$. The two lower down-sloping curves are isoquants along which the repayment rate in absence of selection on ability, $\mu^{A} \rho^{A}$, would exactly equal the minimum profitability, $\underline{\Pi}$, and this minimum plus the cost of selection on wealth, $\underline{\Pi}+C^{w}+C^{s}$, respectively. 
Area $N V$ is one in which the MFI is non-viable. The MFI optimally chooses to do no selection in area $\emptyset$; to induce selection on ability in areas marked $A$; to induce selection on wealth in areas $W$; and to induce selection of clients on both wealth and ability in areas $A W$. A similar figure can be drawn for the reverse case when the cost of acquisition of information on poverty status $C^{w}+C^{s}$ is higher than the cost of acquisition of information on ability $C^{a}$.

We summarize our results in the following proposition:

Proposition 2 No combination of incentives and audit can be ruled out for a pro-poor MFI. Incentives based on repayment are chosen unless there is little gain to be had from selecting out worse performers. Adding an audit appears particularly useful when the proportion of poor borrowers is not too large ( $\mu^{p}$ sufficiently small), while the MFI prefer to forego selection according to wealth if audit costs are high and/or the very poor are prevalent in the population,as in particular geographic areas.

Proposition 2 implies that incentive schemes may not allow to distinguish between for-profit and pro-poor MFIs. The internal functioning of the MFI will not always provide reliable information as a pro-poor MFI can find it optimal to have either no incentives at all, repayment incentives (as a for-profit institution), random audit, or both repayment incentives and random audit. Moreover, the use of an audit procedure is often informal in practice, and not written in labor contracts.

Corollary 1 In some contexts, for-profit and pro-poor MFIs use the same type of incentive schemes - based on repayment only. They may not be distinguishable according to their internal incentives.

What if lending to poor unable borrowers provides social gains? As mentioned in the introduction, lending to poor unable borrowers provides no gain to a pro-poor MFI. This paragraph relaxes this assumption by assuming that poor unable borrowers obtain some nonmonetary gain (as social capital), $\underline{v}$, when obtaining a loan. The expected gain for a poor able borrower, $V$, naturally encompasses this gain, and $V>\underline{v}$. This gain would not be taken into account by a for-profit MFI, but it would matter for a pro-poor MFI. The objective of a pro-poor MFI would now be $y_{A}^{p}(\alpha+V)+y_{U}^{p}(\underline{v})$. 
As $\alpha+V>\underline{v}$, it remains optimal to lend primarily to poor able borrowers when this is not too costly. But the comparison between the four options studied is slightly modified: The value of each option for a pro-poor MFI is unchanged for options $[a]$ and $[a, w]$ but is now

- $\mu^{p}\left(\mu^{A}(\alpha+V)+\left(1-\mu^{A}\right) \underline{v}\right)$ for option $[\emptyset]$ (an additional benefit $\left.\mu^{p}\left(1-\mu^{A}\right) \underline{v}\right)$ compared to our case),

- and $\frac{\mu^{A}-\left(\underline{\Pi}+C^{w}+C^{s}\right)}{1-\alpha}\left[\alpha+V+\frac{1-\mu_{A}}{\mu_{A}} \underline{v}\right]$ for option $[w]$ (an additional benefit $\left.\frac{\mu^{A}-\left(\underline{\Pi}+C^{w}+C^{s}\right)}{1-\alpha} \frac{1-\mu_{A}}{\mu_{A}} \underline{v}\right)$.

Not offering incentive schemes and offering incentives based only on wealth thus become more attractive to a pro-poor MFI; this is of course more so if the value obtained by poor unable borrowers, $\underline{v}$, is large, and if the proportion of able borrowers in the pool of individuals, $\mu^{A}$, is small.

\subsection{Evidence on the use of poverty audits}

There is evidence that social performance indicators are starting to be used by pro-poor MFIs in rewarding their credit agents, in addition to widespread use of incentives based on indicators of repayment performance (see Grammling and Holtman, 2006, 2008; and the discussion on MicroLINKS, 2008). There is agreement that staff incentive schemes focused only on financial goals - with indicators such as loan portfolio quality, portfolio size, and client loyalty - can undermine meeting social objectives as they push agents to work with larger and less risky borrowers (as analyzed in Section 4 of this paper).

MFIs concerned with social performance have focused first on instruments other than staff incentive schemes: They have targeted geographical areas with high poverty rates, and they have used product design, such as small loan size and frequent repayments, that induce self-selection by the poor. Examples are Equity Bank in Kenya and BancoSol in Bolivia (Grammling and Holtman, 2008). As this has proved insufficient in avoiding mission drift on a broader scale, staff incentive schemes are the object of increasing attention. Interesting initiatives are emerging that show signs of evolving toward a credit agent-level audit system as proposed in this paper. AMK in Cambodia uses twice-yearly staff performance assessments based on both financial and social performance indicators. Outcomes of these assessments affect rewards given to agents. PRIZMA in Bosnia and Herzegovina is the only MFI that we know of which reports having a poverty goal explicitly built in its staff incentive scheme. At the branch level, client 'poverty scorecards' 
(i.e., client wealth audits) are used to assess the percentage of poor among new customers, determining branch-level awards. Monthly bonuses are also determined at the individual agent level that are strictly based on financial productivity but that avoid introducing social biases toward larger clients. Indicators include number of disbursed loans and number of clients, but do not reward portfolio size. In our judgment, branch-level audits of social objectives combined with individual incentives to meet financial objectives may lead to free riding of agents on branch performance. Introducing individual agent audits of the same type as done at the branch level would seem to be a better option, as recommended in this paper.

Progress has been made in specifying indicators that can be used to rate MFIs - or their branches - on their social performance. Cerise (2008) is an alliance of four research institutes and NGOs that has proposed a set of indicators to rate the social performance of a microfinance institution. This methodology is used by MFIs in Morocco, Mexico, Cambodia, Albania, Philippines, Ethiopia, Guinea, Mali, Bolivia, and Madagascar (Cruz, 2007). It is also used by NGOs such as Trias in Belgium and the PROSPERA (Promotion of Social Performance) MFI network. Indicators developed to measure an MFI's or a branch's degree of inclusion of poor clients can readily be used to rate the performance of individual credit agents in the random audits suggested here.

\section{Mission drift and viability of pro-poor MFIs}

\subsection{Cross-subsidization and competition between MFIs}

There has been a rapid rise in competition among MFIs for good borrowers (McIntosh, de Janvry, and Sadoulet, 2005). Rising competition is particularly threatening to pro-poor MFIs. We have abstracted from this issue to this point by considering a single MFI. This section discusses the impact of competition on the possibility of using cross-subsidization and on incentives for agents (we do not discuss other aspects of rising competition such as multiple loan taking, see McIntosh and Wydick, 2005). Competition to recruit and keep their good borrowers implies that MFIs (either for-profit or pro-poor) must offer better terms to rich able borrowers. This substantially reduces the opportunity for cross-subsidization by pro-poor MFIs.

Consider a for-profit and a pro-poor MFI operating on the same market (or geographical area). If the pro-poor MFI wants to attract some of the richer borrowers, it has to offer loan 
contracts that are at least as profitable to borrowers as the ones offered by a for-profit MFI. But a for-profit MFI faces lower incentive costs, as it does not have to audit selected borrowers. A for-profit MFI thus benefits from a competitive advantage due to lower internal costs. The assumptions made as to the type of competition between MFIs matter: With the equivalent of Bertrand competition, a for-profit MFI lowers its per borrower profits until the pro-poor MFI is not able to follow suit. The pro-poor MFI can no longer use cross-subsidization as it is excluded from the market of rich able borrowers.

In practice, however, pro-poor MFIs often have access to subsidized funding, so that their viability constraint may be less severe than in for-profit institutions (프 is likely to be lower in a pro-poor institution), and they may be able to effectively compete with a for-profit MFI, and to compensate for their higher internal costs by their lower profitability target, maintaining financial viability and cross-subsidization. Our main results may thus be robust to competition, as long as pro-poor MFIs are sufficiently subsidized. ${ }^{21}$

Competition among pro-poor MFIs will tend to reduce their access to subsidized funds, obliging them to refinance a part of their loans at higher rates. This would be modeled in our setting by an increase in $\underline{\Pi}$. In addition, when several pro-poor MFIs lend to the same pool of borrowers, competition for the best clients imply a lower profitability for each institution. In our model, it then becomes more likely that audit costs are too large for the MFI to induce information acquisition on wealth.

Competition is also becoming fiercer for agents who have accumulated a high value asset in the form of private information on their clientele. Agents' turn-over seems to be important in all regions. Retaining agents with a good knowledge of the clientele requires offering them better wages, which reduces the number of loans that pro-poor MFIs can offer. In our model, this can be formalized as an increase in the minimum profit to be obtained, $\underline{\Pi}$. Indeed, we have normalized the outside option of the agent to zero. If competition leads to an increase in this outside option by some amount $\Delta$ (competition drives wages up), this translates, in our risk neutral setting, into an increase in the agent's wage by $\Delta$ (as the participation constraint of the agent is always binding). It is thus formally similar to an increase by $\Delta$ in the minimum profitability level, ㅍ. Thus, more competition for agents has the same consequences, formally,

\footnotetext{
${ }^{21}$ Competition therefore constitutes an additional justification for offering subsidies to pro-poor institutions - a potential problem being the fact that for-profit MFIs may pretend that they have pro-poor objectives in order to benefit from such subsidies.
} 
as more competition for funds.

With rising competition, a pro-poor MFI that faces a stringent budget constraint will increasingly behave as a for-profit MFI since it then primarily lends to more profitable, richer, borrowers. Competition for agents, like direct competition between MFIs, makes it more likely that the poorest individuals will not obtain financing, contributing to the observed mission drift.

\subsection{Conclusion}

We have shown how a positive correlation between wealth and repayment gives rise to problems in designing internal incentives for agents in pro-poor MFIs. In particular, random audits on the wealth of borrowers selected by agents, together with bonuses based on repayment, appear necessary to ensure that credit agents adequately select borrowers on the basis of both ability to repay and poverty levels. Auditing is particularly important for a pro-poor MFI when borrowers differ in terms of wealth - i.e., a sufficient proportion of them is not very poor - and when lending to able borrowers is sufficiently profitable to cover the added costs of the audit procedure. In practice, because wealth verification of individual borrowers through household interviews is expensive, random audits making use of easily verifiable and low-cost poverty indicators have been introduced (see Gibbons, 1998, and Cerise, 2008). While these indicators are intended to be applied at the level of a pro-poor MFI or each of its branches, they can equally well be used to monitor the selection performance of individual credit agents.

When costs of acquisition of information on wealth and auditing are high and the share of very poor in the population of potential borrowers is large, an MFI will prefer to give incentives to agents to select on ability only. In this case, pro-poor targeting can be done by selecting impoverished geographical areas or by using financial products that are only attractive to poor borrowers, two widely used approaches. However, because this will leave large areas uncovered and has a cost on the poor, improving methods to gather information on wealth and carry low-cost audits is a priority to prevent mission drift among pro-poor MFIs. 


\section{Appendices}

\section{Appendix 1: The objective of a pro-poor MFI}

We assume that a pro-poor MFI wants to maximize the welfare of poorer individuals. It faces a viability constraint, and constraints on repayment, as borrowers cannot reimburse more on average than their gain from the project they undertake. We do not rule out negative average repayments (direct aid to borrowers). For simplicity, we focus below on the situation in which the MFI is informed, at some cost $C$ (possibly $C^{a, w}+C^{s}$ ).

Let $y_{i}^{k}$ be the proportion of borrowers of ability $i, i=A, U$, and wealth $k, k=p, r$ selected by the MFI, and $R_{i}^{k}$ the (possibly negative) repayment required from them. The program of an informed pro-poor MFI is:

$$
\begin{array}{ll} 
& \max _{\left\{y_{i}^{k}, R_{i}^{k}\right\}_{i=A, U, k=p, r}}\left\{y_{A}^{p}\left(\alpha+V-R_{A}^{p}\right)+y_{U}^{p}\left(0-R_{U}^{p}\right)\right\} \\
\text { s.t. } & R_{A}^{p} \leq \alpha, R_{U}^{p} \leq 0, R_{A}^{r} \leq 1, R_{U}^{r} \leq 0 \\
& \sum_{k, i} y_{i}^{k}=1 \\
& y_{A}^{p} R_{A}^{p}+y_{A}^{r} R_{A}^{r} \geq \underline{\Pi}+w+C
\end{array}
$$

Let us note the following:

- As $R_{U}^{r}$ must be at most zero and neither $R_{U}^{r}$ nor $y_{U}^{r}$ enter the objective of the MFI, it is clear that $y_{U}^{r}$ must be set equal to zero (as it would otherwise reduce the proportions of borrowers from other types without providing financial resources).

- As the gross gain obtained from lending to able poor borrowers is larger than for unable ones $(\alpha+V>0)$ it is always improving to increase $y_{A}^{p}$ by one unit while simultaneously reducing $y_{U}^{p}$ to leave the total proportion of poor borrowers unchanged (it improves the objective while relaxing the viability constraint). We obtain a bang-bang solution with respect to these two proportions: $y_{U}^{p}=0$, so as to allow more lending to able poor borrowers.

- $R_{A}^{r}$ must be set to its maximal value, 1 , so as to relax the viability constraint, without affecting the objective of the MFI.

The program thus rewrites as:

$$
\begin{array}{ll} 
& \max _{y_{A}^{p}, R_{A}^{p}}\left\{y_{A}^{p}\left(\alpha+V-R_{A}^{p}\right)\right\} \\
\text { s.t. } & R_{A}^{p} \leq \alpha \\
& y_{A}^{p} R_{A}^{p}+\left(1-y_{A}^{p}\right) \geq \underline{\Pi}+w+C
\end{array}
$$


As $R_{A}^{p} \leq \alpha<\underline{\Pi}<1$, the viability constraint must be binding. A non-binding constraint would allow an improvement in the objective thanks to an increase in $y_{A}^{p}$.

Suppose now that $R_{A}^{p}$ is lower than its maximal level $\alpha$, so that $\alpha-R_{A}^{p}=X$. By reducing $X$ to zero, one can increase $y_{A}^{p}$ by $\frac{y_{A}^{p} X}{\alpha}$ while still having the viability constraint binding. This generates a change in the objective of the MFI of $-y_{A}^{p} X+\frac{y_{A}^{p} X}{\alpha} V$. This change is always positive for $\alpha \leq V$.

For a large enough future gain of getting a loan for able borrowers $(V \geq \alpha)$, it is optimal for the MFI to have $y_{i}^{U}=0, i=p, r, R_{A}^{r}=1, R_{A}^{p}=\alpha$, and $y_{A}^{p}$ as high as is compatible with the viability constraint.

The problem of a pro-poor MFI is thus to maximize $y_{A}^{p}$ subject to a binding viability constraint.

When selection is done with no or only partial information, the viability constraint may no longer be binding as the MFI will not be able to have it so. The above reasoning however applies, so that the objective of the objective of the MFI remains maximizing $y_{A}^{p}$.

Assume here for the sake of completeness that poor unable borrowers obtain some small non-monetary benefit, say $\underline{v}$, from getting a loan. This gain can be assumed to be incorporated in $V$ for poor able borrowers, as it is reasonable to assume that $V$ is much larger than $\underline{v}$. The above analysis would still hold, as $\alpha+V>\underline{v}$ : lending primarily to as many poor able borrowers as possible remains optimal, as noted in the second point above. The simplifying assumption we retain in the text $(\underline{v}=0)$ is thus without loss of generality for this point.

\section{Appendix 2. Inducing information acquisition on ability and wealth}

We focus in this Appendix on the establishment of the incentive contract for the agent. We therefore abstract for now from the financial viability constraint. If the pro-poor MFI wants to induce information acquisition on both wealth and ability, the constraints are:

$$
\begin{aligned}
& \mathcal{U} \geq 0 \quad(P C) \\
& \mathcal{U} \geq \max _{x^{p} \in[0,1]}\left\{w\left(\sigma\left(x^{p}\right), 1-(1-\alpha) \mu^{A} x^{p}\right)\right\}-C^{w}(I C)^{a} \\
& \mathcal{U} \geq \max _{x_{A} \in[0,1]}\left\{w\left(\sigma\left(\mu^{p}\right), 1-(1-\alpha) \mu^{p} x_{A}\right)\right\}-C^{a}(I C)^{w} \\
& \mathcal{U} \geq w\left(\sigma\left(\mu^{p}\right)\right), \mu^{A}\left(1-(1-\alpha) \mu^{p}\right) \quad(I C)^{a, w},
\end{aligned}
$$

where $\mathcal{U} \equiv w\left(\sigma\left(y_{A}^{p}\right), 1-(1-\alpha) y_{A}^{p}\right)-C^{a, w}$ is the agent's utility when obeying the MFI (the constraint ensuring that the agent selects adequate proportions when he is informed will be satisfied in a linear scheme with $\omega \geq \lambda$ ).

We focus on linear wage schemes. Choosing unable borrowers only reduces the bonus based on repayment without modifying the penalty based on the selection on wealth, so the incentive 
constraint $(I C)^{w}$ simplifies, as the agent chooses only able borrowers. We get $\mathcal{U}=W+\omega[1-$ $\left.y_{A}^{p}(1-\alpha)\right]-s \mathbf{E}|\epsilon|-C^{a, w}$ and:

$$
\begin{array}{lcl}
\mathcal{U} \geq & 0 & (P C) \\
\mathcal{U} \geq & \max _{x^{p}}\left\{\omega\left[1-x^{p}(1-\alpha)\right] \mu^{A}-s \mathbf{E}\left|y_{A}^{p}-\left(x^{p}+\epsilon\right)\right|\right\}+W-C^{w} & (I C)^{a} \\
\mathcal{U} \geq & \omega\left[1-\mu^{p} x_{A}(1-\alpha)\right]-s \mathbf{E}\left|y_{A}^{p}-\left(\mu^{p}+\epsilon\right)\right|+W-C^{a} & (I C)^{w} \\
\mathcal{U} \geq & \omega\left[1-\mu^{p}(1-\alpha)\right] \mu^{A}-s \mathbf{E}\left|y_{A}^{p}-\left(\mu^{p}+\epsilon\right)\right|+W & (I C)^{a, w} .
\end{array}
$$

Let us construct a wage scheme that satisfies all constraints.

To simplify $(I C)^{a}$, we must compute the number of poor $x^{p}$ chosen by the agent when informed on wealth only. As $x^{p}$ enters the wage linearly, its value depends on the sign of its multiplier: $x^{p}=0$ if $s<\omega(1-\alpha) \mu^{A}$, and $x^{p}=y_{A}^{p}$ otherwise. And $x_{A}=1$ as wages increase in repayment. Last, $(P C)$ binds in equilibrium. Assume $s \geq \omega(1-\alpha) \mu^{A}$; then the relevant constraints are

$$
\begin{aligned}
C^{a, w}-\omega\left[1-y_{A}^{p}(1-\alpha)\right]-s \mathbf{E}|\epsilon| & =W(P C) \\
\omega\left(1-\mu^{A}\right)\left[1-y_{A}^{p}(1-\alpha)\right] & \geq C^{a, w}-C^{w}(I C)^{a} \\
\omega\left(\mu^{p}-y_{A}^{p}\right)(1-\alpha)+s\left[\mathbf{E}\left|y_{A}^{p}-\left(\mu^{p}+\epsilon\right)\right|-\mathbf{E}|\epsilon|\right] & \geq C^{a, w}-C^{a}(I C)^{w} \\
\omega\left[1-\mu^{A}-\left(y_{A}^{p}+\mu^{A}\left(1-\mu^{p}\right)\right)(1-\alpha)\right]+s\left[\mathbf{E}\left|y_{A}^{p}-\left(\mu^{p}+\epsilon\right)\right|-\mathbf{E}|\epsilon|\right] & \geq C^{a, w}(I C)^{a, w} .
\end{aligned}
$$

As $\omega$ and $s$ always enter the constraints with the same sign, increasing one does not create conflicts. To characterize one of the many possible solutions in terms of $\omega$, let us take $s=$ $\omega(1-\alpha) \mu^{A}$. Then $W=C^{a, w}-\omega\left[1+(1-\alpha)\left(-y_{A}^{p}+\mu^{A} \mathbf{E}|\epsilon|\right)\right]$. The constraints become:

$$
\begin{aligned}
\omega & \geq \omega^{1} \equiv \frac{C^{a, w}-C^{w}}{\left(1-\mu^{A}\right)\left[1-y_{A}^{p}(1-\alpha)\right]} \quad(I C)^{a} \\
\omega & \geq \omega^{2} \equiv \frac{C^{a, w}-C^{a}}{(1-\alpha)\left[\mu^{p}-y_{A}^{p}+\mu^{A}\left(\mathbf{E}\left|y_{A}^{p}-\left(\mu^{p}+\epsilon\right)\right|-\mathbf{E}|\epsilon|\right)\right]} \quad(I C)^{w} \\
\omega & \geq \omega^{3} \equiv \frac{C^{a, w}}{1-\mu^{A}+(1-\alpha)\left[-y_{A}^{p}+\mu^{A}\left(-1+\mu^{p}+\mathbf{E}\left|y_{A}^{p}-\left(\mu^{p}+\epsilon\right)\right|-\mathbf{E}|\epsilon|\right)\right]} \quad(I C)^{a, w} .
\end{aligned}
$$

A solution is $s=\omega(1-\alpha) \mu^{A}, \omega=\max \left\{\lambda, \omega^{1}, \omega^{2}, \omega^{3}\right\}$ and $W$ computed as noted above.

Information acquisition on wealth only, or ability only, can similarly be obtained.

We sketch here the case of information on wealth only: To ensure that the agent acquires information on both wealth and ability (in which case he then chooses $x_{A}^{p}=y^{p}$ for $s$ large), one must have $\omega \mu^{A}\left(1-y^{p}(1-\alpha)\right)-C^{w} \geq \omega\left(1-y^{p}(1-\alpha)\right)-C^{a, w}$, which is satisfied for $\omega \leq \hat{\omega} \equiv \frac{C^{a, w}-C^{w}}{\left(1-\mu^{A}\right)\left(1-y^{p}(1-\alpha)\right)}$. To ensure that he does not acquire information on ability rather than wealth, one must have $\omega \mu^{A}\left(1-(1-\alpha) y^{p}\right)-s \mathbf{E}|\epsilon|-C^{w} \geq \omega\left(1-(1-\alpha) \mu^{p}\right)-s \mathbf{E}\left|y^{p}-\left(\mu^{p}+\epsilon\right)\right|-C^{a}$. 
This is satisfied for $s \geq \frac{C^{a}-C^{w}+\omega\left[1-\mu^{A}+(1-\alpha)\left(y^{p} \mu^{A}-\mu^{p}\right)\right]}{\mathbf{E}\left|y^{p}-\left(\mu^{p}+\epsilon\right)\right|-\mathbf{E}|\epsilon|}$. Last, to ensure that the agent becomes informed on wealth rather than select randomly, one must have $\omega \mu^{A}\left(1-(1-\alpha) y^{p}\right)-s \mathbf{E}|\epsilon|-C^{w} \geq$ $\omega \mu^{A}\left(1-(1-\alpha) \mu^{p}\right)-s \mathbf{E}\left|y_{A}^{p}-\left(\mu^{p}+\epsilon\right)\right|$. This is ensured if $s \geq \frac{C^{w}+\omega \mu^{A}(1-\alpha)\left(y^{p}-\mu^{p}\right)}{\mathbf{E}\left|y^{p}-\left(\mu^{p}+\epsilon\right)\right|-\mathbf{E}|\epsilon|}$. A sufficiently large penalty $s$ is thus sufficient, provided $\lambda \leq \omega \leq \hat{\omega}$; A possible solution is the one provided in footnote 20 .

\section{Appendix 3. How much information acquisition to induce?}

The regions drawn on Figures 1 are characterized as follows.

1. Option $\emptyset$ (no incentives) is feasible (but not necessary optimal) if $\mu^{A} \rho^{A}-\underline{\Pi} \geq 0$. This corresponds to all areas above the $\mu^{A} \rho^{A}-\underline{\Pi}=0$ curve, i.e., all areas except $N V, A_{3}$, and $A W_{3}$ in Figure 1.

2. If $\rho^{A} \geq \underline{\Pi}+C^{a}$ (areas $A, W_{1}$, and $A W$ ), the MFI can afford the cost of selection on ability and would reach more able poor if it does, as $\mu^{p} \geq \mu^{p} \mu^{A}$, with a positive net profit of $\rho^{A}-\underline{\Pi}-C^{a}$. Repayment incentives (option $a$ ) are thus better than no incentive, $(\emptyset)$ ), in this area. Note that there may be cases (areas $A_{3}$ and $A W_{3}$ ) when an MFI would not be viable without incentives $\left(\mu^{A} \rho^{A}<\underline{\Pi}\right)$, while it could make a profit with repayment incentives $\left(\rho^{A} \geq \underline{\Pi}+C^{a}\right)$ : this happens if $\mu^{A}$ is very low, so that selecting on ability makes a crucial difference in meeting the budget constraint.

3. Comparing options $a$ and $a, w$ in Table 2, one can show that incentives on both repayment and targeted share of poor will allow the MFI to include more able poor that under repayment incentives only if $\rho^{A} \geq \underline{\Pi}+C^{a, w}+C^{s}$ (areas $A W$ ). Hence, if profits could cover the corresponding information and auditing costs, the MFI could use selection on wealth to increase the proportion of poor.

4. Comparing now options $\emptyset$ and $a$, one can show that if $\mu^{A} \rho^{A} \geq \underline{\Pi}+C^{w}+C^{s}$ (i.e. the profits obtained when not giving incentives cover the costs of incentives for selection of the poor), as in areas $A_{1}, W_{1}, W_{2}$ and $A W_{1}$, the MFI could have its agents select a higher proportion of poor borrowers than their share in the population with an incentive scheme based on achieving the targeted proportion of poor.

5. Finally, there may be cases where $\mu^{A} \rho^{A} \geq \underline{\Pi}+C^{w}+C^{s}$ and $\rho^{A} \geq \underline{\Pi}+C^{a}$, but $\rho^{A} \leq$ $\underline{\Pi}+C^{a, w}+C^{s}$ (area $A_{1}$ and $W_{1}$ ), meaning that the MFI can select on either wealth or ability, but not on both. Comparing the number of poor under options $a$ and $w$, one can show that the MFI prefers to select on wealth alone rather than on ability alone if $\frac{\mu^{A}-\left(\underline{\Pi}+C^{w}+C^{s}\right)}{(1-\alpha)}>\mu^{p}$, which implies that $\left(\mu^{A}+\rho^{A}\right)>1+\underline{\Pi}+C^{w}+C^{s}$. This is represented in area $W_{1}$. 


\section{References}

Amin, S., Rai, A.S., and Topa, G., 2003. Does Microcredit Reach the Poor and Vulnerable?

Evidence from Northern Bangladesh. Journal of Development Economics, 70(1), 59-82.

Armendáriz de Aghion, B., and Gollier, C., 2000. Peer Group Formation in an Adverse Selection Model. The Economic Journal, 110(465), 632-43.

Armendáriz de Aghion, B., and Morduch, J., 2005. The Economics of Microfinance. MIT Press, Cambridge, MA.

Becker, G.S., 1968. Crime and Punishment: An Economic Approach. Journal of Political Economy, 76(2), 169-217.

Becker, G.S., and Stigler, G.J., 1974. Law Enforcement, Malfeasance, and Compensation of Enforcers. The Journal of Legal Studies, 3(1), 1-18.

Besley, T., and Coate, S., 1992. Workfare versus Welfare: Incentive Arguments for Work Requirements in Poverty Alleviation Programs. American Economic Review, 82(1), 249-61.

Besley, T., and Ghatak, M., 2005. Competition and Incentives with Motivated Agents. American Economic Review, 95(3), 616- 636.

Bond, P., and Rai, A., 2002. Collateral Substitutes in Microfinance. mimeo, CID, Harvard University.

Bond, P., and Rai, A., 2006. Cosigned vs. Group Loans. Journal of Development Economics, $85(1-2), 58-80$.

Cerise. 2008. Indicateurs de performance sociale. www.cerise-microfinance.org

Conning, J., 1999. Outreach, Sustainability and Leverage in Monitored and Peer-Monitored Lending. Journal of Development Economics, 60(1), 51-77.

Crémer, J., and McLean, R., 1988. Full Extraction of the Surplus in Bayesian and Dominant Strategy Auctions. Econometrica, 56(6), 1247- 58.

Cruz, Isabel. 2007. Como saber que las microfinanzas realmente impactan la vida de los pobres?. Boletin Desempeno Social No. 1, http://www.forolacfr.org/

de Wit, J., 1998. Targeting the Poorest and Covering Costs. Countdown 2005 (Newsletter of Microcredit Summit Campaign), 1, 1-2.

Francois, P., 2003. Not-for-Profit Provision of Public Services. The Economic Journal, 113(486), C53-C61.

Fuentes, G. A., 1996. The Use of Village Agents in Rural Credit Delivery. Journal of 
Development Studies, 33(2), 188-209.

Ghatak, M., 1999. Group Lending, Local Information and Peer Selection. Journal of Development Economics, 60(1), 27-50.

Ghatak, M., 2000. Screening by the Company you Keep: Joint Liability Lending and the Peer Selection Effect. The Economic Journal, 110(465), 601-31.

Ghatak, M. and T. Guinnane, 1999. The Economics of Lending with Joint Liability: A Review of Theory and Practice. Journal of Development Economics, 60(1), 195-228.

Gibbons, D., 1998. Cashpor, Countdown 2005 (Newsletter of Microcredit Summit Campaign), 1,3 .

Grammling, Mattias, and Martin Holtmann. 2006. Designing Staff Incentive Schemes to Balance Social and Financial Goals. MicroFinance Network and CGAP, http://www.microlinks.org/ev_en.php?ID=23239_201\&ID2=DO_TOPIC

Grammling, Mattias, and Martin Holtmann. 2008. The Role of Staff Incentive Schemes in Balancing Social and Financial Goals-Evidence from Four MFIs. http://www.microlinks.org/ev_en.php?ID=22431_201\&ID2=DO_COMMUNITY

Hulme, D., 2000. Is Microdebt Good for Poor People? A Note on the Dark Side of MicroFinance. Small Enterprise Development, 11(1), 26-28.

IRIS Center, 2004. Developing Poverty Assessment Tools Project, Final workshop report. The IRIS Center at the University of Maryland, College Park.

Jeon, D-S., and Menicucci, D., 2005. Hierarchy in Microfinance: Embezzlement and the Optimality of Rigid Repayment Schedules and Joint Liability. University Pompeu Fabra Working Paper 893.

Kaboski, J., and Townsend, R.M., 2005. Policies and Impact: An Analysis of Village-Level Microfinance Institutions. The Journal of the European Economic Association, 3(1), 1-50.

Laffont, J.J., 2003. Collusion and Group Lending with Adverse Selection. Journal of Development Economics, 70(2), 329-348.

McIntosh, C., and Wydick, B., 2005. Competition and Microfinance.Journal of Development Economics, 78(2), 271-98.

McIntosh, C., de Janvry, A., and Sadoulet, E., 2005. How Rising Competition Among Microfinance Institutions Affects Incumbent Lenders. The Economic Journal, 115(506): 9871004. 
McKim, A., and Hugart, M., 2005. Staff Incentive Schemes in Practice: Findings from a Global Survey of Microfinance Institutions. MicroFinance Network.

http://www.mfnetwork.org/working_groups/staff_incentives.html

MicroLINKS. 2008.

www.microlinks.org/ev_en.php?ID=23205_201\&ID2=DO_DISCUSSIONPOST_LIST\#day3open

Morduch, J., 1999. The Microfinance Promise. Journal of Economic Literature, 37(4), 1569-1614.

Mookherjee, D., 1997. Incentive Reforms in Developing Country Bureaucracies: Lessons From Tax Administration. in Annual Bank Conference in Development Economics, B. Pleskovic and J. Stiglitz (eds), the World Bank, Washington D.C.

Rai, A., 2002. Targeting the Poor Using Community Information. Journal of Development Economics, 69(1), 71-83.

Riordan, M., and Sappington, D.E.M., 1988. Optimal Contracts with Public ex-post Information. Journal of Economic Theory, 45(1), 189-99.

Rowat, C., and Seabright, P., 2006. Intermediation by Aid Agencies. Journal of Development Economics, 79(2), 469-491.

SEF, Small Enterprise Fund, 2004. Overview, 2003, www.sef.co.za/sef\%20overview/more_about_sef.htm

Sharma, M., and Zeller, M., 1997. Repayment Performance in Group Based Credit Programs in Bangladesh: An Empirical Analysis. World Development, 25(10), 1731-42.

Simanowitz, A., 2004. Ensuring Impact: Reaching the Poorest While Building Financially Self-Sufficient Institutions, and Showing Improvement in the Lives of the Poorest Families. www.microcreditsummit.org/papers/\#5Simanowitz.doc.

Sustainable Banking for the Poor, 2002. Report. http://www.microfinancegateway.org/download/SBP/NGOs_Tom_Final.pdf

Tirole, J., 1986. Hierarchies and Bureaucracies. The Journal of Law, Economics, and Organization, 2(2), 181-294.

Weiss, J., and Montgomery, H., 2005. Great Expectations: Microfinance and Poverty Reduction in Asia and Latin America. Oxford Development Studies, 33(3), 391-416.

Wright, G., and Dondo, A., 2001. 'Are you Poor Enough?': Client Selection in MicroFinance Institutions. Microsave-Africa, Briefing Note 7. 
Zeller, M., 1998. Determinants of Repayment Performance in Credit Groups: The Role of Program Design, Intra-group Risk Pooling, and Social Cohesion. Economic Development and Cultural Change, 46(3), 599-620.

Zeller, M., 2004. Review of Poverty Assessment Tools. The IRIS Center at the University of Maryland. 